\title{
Strategies for the Improvement of Quality of China's Basic Education
}

\author{
Li-na ZHANG ${ }^{1}$, Ming ZHANG ${ }^{2}$, Xiao-dong PAN ${ }^{3}$ \\ 1, 3 Teachers' College, Shenyang University \\ 2 College of Information and Engineering, Shenyang University \\ Shenyang City, Liaoning Province, China \\ 11402678739@qq.com, ${ }^{2}$ zhming_163@163.com, ${ }^{3} 782024347 @$ qq.com
}

\begin{abstract}
This paper is on how to improve the quality of basic education within the current educational reform to react to the massive economic reforms and social development. The focus is also an attempt to raise awareness of the importance and the development value of quality in basic education in China. In order to study the strategies for the improvement of quality of basic education in China, this paper is developed by reviewing the literature on quality of education. The basic strategies for the improvement of quality of basic education are learning, learning environment, teachers, teaching and learning, curriculum and textbook, school management, finance and utilization of resources, as well as assessment of academic achievement. This paper discusses the reform and practice of the improvement of quality of basic education to get the conclusion about teachers. Teachers, as the biggest single resource in the educational system, implement educational policies, interpret the curriculum, as well as influence the achievements of students and outcomes of education directly.
\end{abstract}

Keywords-Strategies; Quality; Basic education; Improvement

\section{INTRODUCTION}

This paper reviews the international literature on what is quality in education and what are the strategies to improve quality in education, so as to stress a first priority of quality in education in China's educational development and reform, thus for good quality education to have wider implications for the integrated development of society and individuals.

In the first section of the paper, entitled 'quality of education', the disparities between descriptions of educational quality are identified and discussed. In this section, I demonstrate the advantages of critical theory which is adopted as a framework for this study. In the second section, the discussions of priority of quality in education are developed at international, national and individual levels. The conceptual frameworks for how to provide education of good quality are presented and discussed. In this section, I draw mainly on the views of stakeholders, who have engaged extensively with the improvement of quality in education.

\section{LITERATURE REVIEW ON QUALITY OF EDUCATION}

In order to discuss how to plan to improve the quality of basic education, it is necessary to define the term of quality in education.

Educational quality is a multi-faceted, all encompassing concept or attribute (Murimba, 2002 cite in Makwati el at. 2003:9) [1]. It is understood in different ways, reflecting the values and priorities of various stakeholders (Williams 2001:85) [2]. Thus, different stakeholders may have different opinions of what quality in education means. Here are several ways of interpreting 'quality' in education.

As shown in the rationale of this study, it is acknowledged that it is not sufficient to increase access to compulsory or basic education, but the content and quality of the education also needs to be considered.

Quality, as inputs and resources, is, according to Williams (2001: 86) an 'extremely common usage of quality.' However, Williams (2001:87) [2] in his research has also found that schools with a similar level of resources often produce quite different results. Infusions of resources often fail to lead to corresponding improvements in outcomes (ibid). The process of what is happening within the school is therefore identified as an important aspect of quality. According to Knutton (1995:24) [3] teachers are the biggest single resource in the educational system, quality education here refers to how teaching and learning processes are, directly involved in deciding the questions needing to be answered and then determining the way they should be tackled. In addition, the content of education is another big resource in the educational system. Quality as content refers to the Knowledge, attitudes, and skills intended to be transmitted through the school curriculum (Williams 2001:87) [2]. The term of 'quality as a process' refers to the need to understand the use of educational inputs (ibid)

Quality as outputs or outcomes involves the consequences of education. Because the focus of the quality of education is always on the consequences of education, 'the adequacy or appropriateness of objects or processes for the purposes for which they were intended' was also related to education of quality (Kellaghan, 2001:22) [4]. Here 'good' or 'poor' quality depends on an object or processes of purposes, which can be met or fail to be met. 
The objects or purposes of education are matters of choice, according to the different roles of education, including students' cognitive achievement, completion rates, certification, individual skills, attitudes, behaviours, moral as well as socially significant. Output of education, e.g. employment, earnings, social development, also the promotion of social and national cohesion (Williams 2001:88) [2]. Even though 'consequences of education are very difficult to measure, the 'consequences' are of vital importance while looking at educational quality. According to the World Bank (1995: 46), the adequate definition of quality in education refers to student outcomes as well the nature of the educational experiences hat help produce those outcomes--the learning environment (Ross and Mahlck 1990, cited in The World Bank 1995:46). UNESCO Regional Office for Education also takes the term 'quality" as outcomes of pupil performance or standards of attainment in different school subjects (UNESCO 1982:62). In this sense, decline in the quality of education means the standards of attainment have gone down, assessed by examination results or other norms of scholastic achievement.

In addition, Malaysia echoes with another useful definition of quality of education as 'the capability of the education system to meet desired standard in term of relevance in curriculum, effectiveness and efficiency in the delivery as well as equality in opportunities for all'(Commonwealth Secretariat 1991:3) [6]. Another voice from Common Secretariat (1991) [6].regards the quality of education as the value and goals of that country's social systems and culture, and in terms of the policies, objectives and practices of its education system (Common Secretariat 1991:6) [6]. In this sense, it refers not only to the economic needs of society but also to promote culture and values.

It is impossible to give a blueprint of what good quality is without a certain context. Different contexts necessitate different kinds of responses, education must be well suited for the culture, economic, end political contexts of the society, otherwise, it will not be successful. According to Hawes and Stephens (1990:13) an important aspect of quality in education is context sensitivity. They write:

Education must be rooted in a society and a culture, which learners can comprehend. An alien education is both unproductive and psychologically disturbing, often leading to a dangerous form of half-learning where children can answer questions on content yet do not fully understand what they are being asked or what they are answering, because it has little connection with their lives and experience (Hawes and Stephens 1990:13) [7].

Any praxis of reflection and action, critique and possibility operates within interrelated contexts both extrinsic and intrinsic to the education system of any particular country.' (Ibid: 34$)$

To summarise, the purpose of this section has been to suggest the significance of quality in education. It is acknowledged that not only 'inputs' necessarily means educational quality but also 'equality a process', not only 'quality as consequences' is vital importance but also context sensitivity. It is clear that a comprehensive definition of quality in education must include five dimensions according to the reviews above: quality as inputs (funds, facilities, teachers as well as textbooks); quality as process (nature of interaction of teaching and learning); quality as content (core curriculum and social activities); quality as consequences (outcomes and outputs of individual and social achievements); as well as quality as contexts (extrinsic and intrinsic environment)

The discussion of this section will enable me to reflect critically upon the priorities of improving quality in education and strategies for its improvement.

\section{LITERATURE REVIEW ON THE IMPROVEMENT OF QUALITY OF BASIC EDUCATION}

In this section a general presentation of reasons of improvement of quality in basic education will be made at international, national and individual level. This is done in order to identify the priority and importance of quality in education. Strategies on the improvement of basic education quality will then be discussed according to the literature review, in order to provide the solid theories for the following case study of China.

\section{A. Why is quality of education important?}

Firstly, at international level, the World Conference on Education for AII, held in Jomtien, Thailand in 1990, has affirmed the imperative not only to ensure education for all children but also to offer education of an acceptable standard for all, which should meet the current and future needs of the learners. According to the statistics from the World Bank and UNICEF, Since 1990, the number of children entering school around the world has been on the increase, which registered an 11 percent gain between 1990 and 1998 in the developing world and 4 million children entered school for the first time in subSaharan Africa (Basic Education Coalition a, 2002:2).However, the problem of the quality of schooling that many children receive has emerged: in some countries, as many as one-third of children complete primary school without learning to read, write, or do simple arithmetic (ibid). Indeed, it is widely accepted that the lack of access to quality basic education or primary education badly limits the benefits individuals can get from schooling socially and economically. It was clear that expanding access alone would not be sufficient for education to contribute fully to the development of the individual and society, however quality in education was defined as a prerequisite for achieving the fundamental goals. Thus the issue of improving the quality of basic education has grown more and more urgent.

A decade later in 2000, the Dakar Framework for Action declared that access to quality education was the right of every child. It affirmed that quality was 'at the heart of education'- a fundamental determinant of enrolment, retention and achievements. More recently, in 2002, at the meeting in Dakar, Senegal, the issue of quality was revisited and stated that:

The Dakar framework for Action gave new impetus to the promotion of quality in education, based on the consensus that expanding access to education will have a beneficial impact on individuals and on society only if the education is of good quality. (UNESCO, 2002:80) 
In the EFA Global Monitoring Report 2005, it is also repeatedly stated that the achievement of universal participant in education will be fundamentally dependent upon the quality of education available (UNESCO, 2004:28). Just as Basic Education Coalition (2002 a: 3) argued that 'deficient education is barely better than no education at all'.

Secondly, at the national levels, the quality in education has been acknowledged as a key aspect in the improvement of general development. For society, undoubtedly education is a cornerstone of economic and social development and basic education is its foundation (Lockheed, E. M. el at 1991:1) [8]. An educated population was seen as more productive; hence improvement in education would lead to economic growth and modernization (Fagerlind and Saha 1989:18) [9]. Studies indicate that significant economic grown usually occurs once a country achieves 80 percent literacy and near universal primary education. Education quality, especially in maths and science, has a sharp impact on economic development (Basic Education Coalition a, 2002:3). It can be argued that China's rapid economic development and great social progress undoubtedly depended on the popularity of basic education which has provided more educated people and more productivity to foster economic growth and social development. According to the statistics, by 2002, the enrolment rate of primary schools and junior secondary schools had been raised to $98.58 \%$ and $90 \%$ respectively. The total enrolment rate of senior secondary schools reached 42.8\% (MoE, PRC, 2002) [10]. On the contrary, low quality in schooling can hinder any long-term benefits that may generate from existing schooling. Fuller (1986) expands upon this theme:

Growing interest in school quality also stems from research emphasizing that the economic benefits of more schooling are limited by low levels of school quality and student achievement. ... recent evidence suggests...economic returns to school depend not only on length of school but also on the level of actual learning that occurs (Fuller 1986:493 cited in Garrett 1999:26).
In addition, many countries also regard improvement of quality in education as a Key element in the establishment of national unity and cultural identity. Educated societies end to promote more broad-based democratic behaviour, peace, rights and political stability (Basic Education Coalition a, 2002:5). Furthermore, leaders in many countries consider the quality of education a critical element in preparing a country and its population to participate effectively in the global economy and also as a means of keeping abreast with scientific and technological advance to enhance the national competitiveness (Commonwealth Secretariat 1991:3) [6].

Thirdly, at the individual level, children can benefit more from the access to quality of education. As well as the basics of reading, writing and arithmetic, they can also learn self-esteem, develop decision-making skills, manage conflict, and respect diversity, which are direct elements to improve their own quality of life (Basic Education Coalition a, 2002:4). In addition, parents have realized that the quality of schooling impact significantly on their children's quality of life and their future life chances, such as greater earning power, expanded job opportunities, better ability to maneuver in a more increasingly complex world and heightened ability to think critically etc, because of the high rate of return in education, particularly in low and middle developing nations (World Bank 1995:21). The Table 1 below is a summary of the rates of return to investment in education for individuals. The contribution of education here is measured 'by comparing the difference in earnings over time of individuals with or without a particular course of education and the cost to economy of producing that education' (World Bank 1995:20-21). According to Table I below, rates of return to education are much higher in low- and mid-income countries than that in high-income countries. It also shows that rates of return are greatest for primary education, followed by secondary and then higher education.

TABLE I. RATES OF RETURN TO INVESTMENT IN EDUCATION FOR INDIVIDUALS BY REGION AND LEVEL OF SCHOOLING

\begin{tabular}{|c|c|c|c|}
\hline Region & Primary & Secondary & Higher \\
\hline Sub-Saharan Africa & 41.3 & 26.6 & 27.8 \\
\hline Asia & 39.0 & 18.9 & 19.9 \\
\hline Latin America, Caribbean & 26.2 & 16.8 & 19.7 \\
\hline Europe, Middle East & 17.4 & 15.9 & 21.7 \\
\hline OECD countries & n.a. & 12.4 & 12.3 \\
\hline
\end{tabular}

In sum, it is obvious that the quality of education is concerned with every part of society from international, national and down to the level of the individual. It is decisive and crucial for the development of individuals, nations and the world. Just as Basic Education Coalition (b 2002) states the quality of basic education as:

Basic education fundamentally influences who we are, what we know, what we believe, how we think, and what we can do. It determines prospects of individuals and nations. It is the basis on which all other aspects of development are founded (Basic Education Coalition, 2002 b http;//www:basiced.org/whybasiced.php, 11.07.05).

Thus, searching for the ways in which to access a goad quality of basic education and planning to improve it should become the priority of educational reforms worldwide. 


\section{STRATEGIES ON THE IMPROVEMENT OF QUALITY OF BASIC EDUCATION}

In the year of 2001, in Dalar, Senegal, the question of improving educational quality was raise during the World Education Forum, 'How to improve quality and performance in universal compulsory education to meet the fundamental goal of lifelong learning for all through sustainable measures' (UNESCO 2003:9). With this aim in mind, policy makers and planners around the world have been seeking approaches for improvement of quality in education in order to meet the needs of the EFA goal as well as education for development. Some strategies to improve the quality of basic education are identified in the various dimensions of quality in education.

$1 \mathrm{t}$ is argued the ultimate target of improvement of quality in education is about social aims of education and outcomes of student learning (OECD 1989). 1t appeared that by definition, '...quality education means education of good quality resulting from a well-planned and well-organised educational process' (Rissom 1992:124) [13]. Here, the educational process included the 'processes of teaching, learning, testing, managing and resourcing' (Jansen 1995:195). Thus teaching and learning supported by wellplanned resources and well-organized management can influence the improvement of quality in education directly.

\section{1) Learning}

Lockheed and Verspoor (1991) [8] argued that students' learning is very important toward the process of producing outcomes of learning, since student achievement is quite supportive to the main goal of education of good quality for all. They identified four factors of educational inputs and process, which are determinant to learning---crriculum, instructional materials, teachers and learner (Lockheed and Verspoor1991:41) [8]. Simultaneously, they also emphasize that 'choosing effective inputs and managing them well is the first step toward improving learning' (ibid: 40).

\section{2) Learning environment}

In addition, for Garrett (1999), the learning environment 'in which the curriculum is transacted; in which the teaching and learning process takes place;' is also at the heart of the effective learning (Garrett1999:51). Good quality environment of schooling can 'well enhance learning, engender the right atmosphere for learning and possibly make the life of teacher easier or more interesting' (ibid).

Just as Adams affirmed that:

Higher levels of inputs, a revitalized, more interactive, learning environment, and specific, practical outputs useful in everyday life are called for as basic building blocks for improved quality (Adams, 1993:39) [16].

\section{3) Teachers}

Undoubtedly, good teachers are the Key to good education; learning outcomes are dependent fundamentally on teacher quality (Garrett 1995: 31, UNESCO 2003:15).In recent important research, Rivkin, Hanushek and Kain (2000) provided the evidence that 'teacher quality is a very important determinant of student learning' and they also found 'the effects of teachers to be much greater than the effects of schools' organization, leadership or financial conditions, in fact, the came to the conclusion that 'teacher quality is the most important aspect explaining student achievement', (OECD 2001:78). Adams (2002:44-47) [17] suggested that the quality of teachers can be raised through:

- Structuring teacher preparation by pre-service or inservice teacher training.

- Certification required by officially sanctioned training programs.

- Providing incentives for teachers by enhancing salaries and other compensations

\section{4) Teaching and learning}

The aim of raising the quality of teachers is to improve the quality of teaching and learning. The heart of teaching and learning lies in learner-teacher interaction in the classroom, According to Bacchus (1991 cited in Garrett 1995:31), teaching skills as the component of improvement of quality in education should be developed, with high quality and relevant training provided to teachers. In addition, Commonwealth Secretariat(1991:22-23) [6] claimed that to be of good quality and effective, teaching strategies and skills should suit he active learning, such as "selection of learning experiences and materials as Situation demands, creation of encouraging environment conductive to learning, Understanding of diagnostic and developmental assessment of pupils ' progress.'

\section{5) Curriculum and textbooks}

The content and structure of the curriculum are important aspects of the teaching and learning process in the classroom. For example, Chapman and Adams (2002) [18] claimed that 'a curriculum specifies the content, sequence, and pacing of what should be taught and learned at classrooms', which affects the outcomes of learning directly either on the learner's 'intellectual, physical, moral, and spiritual development or on the promise of high-paying jobs' (Chapman and Adams 2002:30-31) [18]. The quality of the textbooks, materials and their plentiful supply has also been found to be a key element associated with effective learning (Commonwealth Secretariat 1991) [6].

\section{6) School management}

Garrett (1995) argued that for teaching and learning to be good and effective, it is not only dependent on quality teachers, quality of curriculum and textbooks, learning environment as Well as teaching strategies, an efficient and effective management system is also crucial to quality improvement in teaching and learning (Garrett1995:45). Furthermore, in relation to quality in education and educational management, he claimed that:

For there to be a sustained improvement in the quality of education, there is a crucial role for management within the education system and this can be summed up m the concept of productive involvement, whereby bureaucracy is set at a minimum for the needs of efficient management and the emphasis is upon a team approach to the issues within primary education which is focused at the local level and Sustained through a flexible support system. (Ibid: 47)) 


\section{7) Finance and utilization of resources}

In general, the efforts towards improvement of quality in education depend largely on the input of finance to education from central and local administration as well as its effective utilizations in the schools. (Commonwealth Secretariat 1991:20) [6]. For example, Verspoor (1989: 1) argued that:

Considerable investments in education during the last three decades by governments have led to an impressive increase in the number of children enrolled in schools throughout the developing world. However, the unfavorable economic environment of the 19805 and resulting scarcity of resources jeopardizes further the ability of developing countries to provide quality education.

Thus due to the increasing constraints of economics and finance, on the improvement of quality education, the Primary concern was to utilize the limited resources effectively and efficiently

\section{8) Assessment of academic achievement}

The importance of improving quality in education not only focuses on inputs and process of learning, but also on the outcomes in terms of learning achievement. An argument from UNESCO (2003) is that curriculum, an enabling environment for learning, Support systems, governance in primary education as well as assessment and evaluation, are all indispensable parts to improve quality in education (UNESCO2003:10-12). In addition, Kellaghan and Greaney (2001: 7) [4] argue that to improve the equality in education, assessment is an important Key, which is responsible for identifying problems of educational system, school level or individual learners. Some authors argued that monitoring, evaluating and indicating the quality of educational provision in input, process and output, and seeking better means of doing so, was an international need and concern (Puryear1995).

From the brief review in this section, it appears that to improve quality in education the Key inputs, process and outcomes of quality in education are all involved

- Teaching and learning methods

- Curriculum and textbooks

- learning environment

- School management

- Finance and utilization of resource

- Assessment of academic achievement

Below is an input-process-Output framework for assessing educational quality, presenting a model of the real process of development of quality in education.-Because there is always a gap between criteria and reality, the implementation of these indicators must vary greatly according to the different circumstances in terms of context sensitivity (UNESCO 2002:80). Just as Smith (1997) suggested that all quality relates to the context in which it is being considered and this in turn alters with time, thus progression is of vital regard (Smith, 1997 cited in Garrett, R. 1999:53).

\section{SUMMARY}

This paper has reviewed the literature on educational quality in general and literature on priorities and strategies for the improvement of quality in education. It has developed a conceptual framework in terms of inputprocess-output for educational quality and I have applied an approach to interrogate the literature on quality. The conceptual framework on priorities of improvement of educational quality was developed, with reference to the discussion at international, national and individual levels. It was then argued that not only quality as inputs and process means improvement of educational quality, but that quality as consequences and sensitivity' say more about the longterm benefit for the society as well as individuals. It was argued that teachers are the biggest single resource in the educational system and that it is they who implement educational policies, interpret the curriculum and influence the achievements of students, outcomes and output of education directly.

\section{REFERENCES}

[1] Makwati, G, Audinos, B. and Lairez, T. (2003) The rote of statistics in improving quality of basic education in Sub-Saharan Africa. http://www.adeanet.org/ biennial2003/papers/2c_ Nesis_ ENG final.pdf.

[2] Williams, J. H. (2001) On School Quality and Attainment in Crisp, J., Talbot-nd Cino Hone. D. Learning For a Future : Refugee education in Developing Countries Switzerland: UNHCR.

[3] Knutton, S. (1995) Aid and Teacher Professionalism in Aid and Education Mending or Spending Bristol Centre for International Studies in Education I P.89- 114.

[4] Kellaghan, T. and Greaney, V. (2001) Using Assessment Io Improve the Quality of Education Paris 2001 UNESCO : International Institute for Educational Planning.

[5] Ming Zhang (2016.12) Research on the Construction of Innovation Education Curriculum System in Science and Engineering Advances in Social Science. Education and Humanities Research.

[6] Commonwealth Secretariat (1991) Improving the Quality of Basic Education. Education Programme Commonwealth Secretariat.

[7] Hawes, H. and Stephens, D. (1990) Question of Quality Primary Education and Development. Longman Grunp Ltd.

[8] Lockheed, E. M. and Verspoor, M. A. (1991) Improving Primary Education in Developing Countries The World Bank publication Oxford University Press.

[9] Fagerlind, I. and Saha J. L. Education and national development: a Comparative perspective (1989) ( $2^{\text {nd }}$ ed.) Oxford: Pergamon Press.

[10] MoE P.R. C (2002) http://www.more.edu. cn/english/basic_b.htm.

[11] Ming Zhang (2016.08) Exploration and Research on the Feature of Practical Teaching in Science and Engineering. Asia-Pacific Journal of Education.

[12] Garren, R. and Smith, B. (1999) Turning aid policy into practice: operationalising NORAD's principles (ed.) Bristol: Centre for international Studies in Education Bristol papers in education Comparative and International studies.

[13] Rissom, Hans-Wolf, (1992). The search for quality in education some comments on the international dimension, in Vedder, P., (ed) 1992 Measuring the quality of education. Amsterdam: Swets\&Zeitlinger.

[14] Jason, J. D. (1995) Effective Schools Comparative Education V31 (2) 
[15] Ming Zhang (2016.08) Research on the Construction of Innovation Education Curriculum System of industry-education integration. Curriculum Education Research.

[16] Admas, D. (1993) Defining Education quality Education planning V9 (3).

[17] Adams, D. (2002) Education and national development priorities, policies and planning Manila: Asian Development Bank; Hong Kong. Comparative Education Research Centre. University of Hong Kong.

[18] Chapman, D. and Adams, D. (2002). The quality of education dimensions and strategies Manila: Asian Development Bank: Hong Kong Comparative Education Research Centre. University of Hong Kong.

[19] Purer, J. K. (1995) International education statistics and research: status and problems International Journal of Educational Development, V15.

[20] Ming Zhang (2016.08) Reform Exploration into Training Mode of Applied Talents in Science and Engineering. Exploration of Intellectual Resources. 